\title{
Divided land base and overlapping forest tenure in Alberta, Canada: A simulation study exploring costs of forest policy
}

\author{
by Steven G. Cumming ${ }^{1}$ and Glen W. Armstrong ${ }^{2}$
}

\begin{abstract}
The forest planning environment in Alberta is complicated by multiple forms of forest tenure and by an arbitrary division of the forest into separate softwood and hardwood land bases. The area within and surrounding the Alberta-Pacific Forest Industries Inc. Forest Management Agreement (FMA) area exemplifies the problem, with a large number of independent forest products companies operating in the area. We model 17 sawmill operators and the Alberta-Pacific pulp mill trying to simultaneously satisfy their mill feedstock requirements from a forest.

We examined the inefficiencies introduced by this tenure system using Tardis, a computer simulation model incorporating access development, timber harvest, and regeneration. We examined two scenarios: one representing the business-as-usual case where the 18 forest products companies are operating independently, and one where the forest is managed by one company that harvests timber and delivers it to each of the mills.

The costs of the present tenure arrangements are, we believe, substantial enough to warrant a thorough re-examination of forest policy and tenure arrangements in Alberta, specifically with respect to land base designation and overlapping tenures.
\end{abstract}

Key words: forest tenure, simulation modelling, timber harvest scheduling, policy analysis

La planification forestière de l'environnement en Alberta est rendue difficile par suite des multiples formes de tenure forestière et par une division arbitraire de la forêt selon des territoires de bois résineux et feuillus. Le territoire couvrant le contrat d'aménagement forestier d'Alberta-Pacific Forest Industries est un exemple de ce problème, une superficie qui compte un grand nombre de compagnies indépendantes de produits forestiers à l'oeuvre dans cette région. Nous avons modelé 17 scieries et l'usine de pâte d'Alberta-Pacific qui tentent simultanément de répondre aux besoins d'approvisionnement de leurs usines à partir de la forêt.

Nous avons étudié les inefficacités introduites par ce système de tenure au moyen de Tardis, un modèle de simulation informatique qui incorpore le développement des accès, la récolte de matière ligneuse et la régénération. Nous avons examiné deux scénarios: l'un représentant la situation normale de travail ou les 18 entreprises de produits forestiers oeuvrent indépendamment, et un autre où la forêt est aménagée par une compagnie qui récolte la matière ligneuse et livre le bois à chaque usine.

Les coûts du système actuel de tenure sont, selon notre perception, suffisamment substantiels pour garantir un réexamen complet de la politique forestière et du système de tenure en Alberta, spécialement au niveau de la désignation du territoire et des tenures qui ses chevauchent.

Mots-clés: tenure forestière, modélisation par simulation, calendrier de récolte de la matière ligneuse, analyse des politiques

\section{Introduction}

Of the 25.7 million ha of productive timber land in the Province of Alberta, Canada, 22.5 million ha (87\%) are publicly owned land under the control of the provincial government. Harvesting rights to most of this land have been allocated to firms under two forms of tenure: Forest Management Agreements (FMAs) and timber quotas. A Forest Management Agreement is a longterm negotiated agreement between the province and a company to harvest, re-establish, and grow timber on a defined land area. As part of the forest management planning process, the FMA holder determines an annual allowable cut (AAC) for the FMA area, which is intended to be a perpetually sustainable level of timber harvest. Quotas, in contrast, are volume-based tenures. The government forest management agency (Alberta Land and Forest Service) determines the AAC for administrative units known as Forest Management Units (FMUs). A timber quota within an FMU represents a per-

\footnotetext{
${ }^{1}$ Boreal Ecosystems Research Ltd., 6915 - 106 Street NW, Edmonton, AB, T6H 2W1. E-mail: stevec@berl.ab.ca

${ }^{2}$ Department of Renewable Resources, University of Alberta, Edmonton AB T6G 2H1. E-mail: glen.w.armstrong@ualberta.ca
}

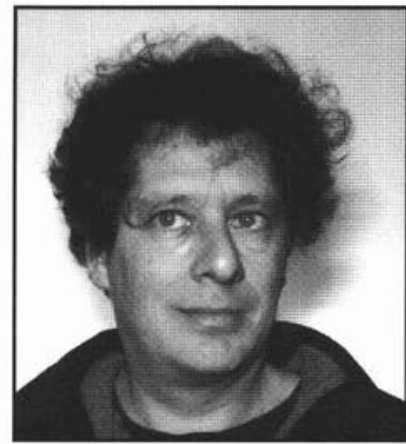

Steven Cumming

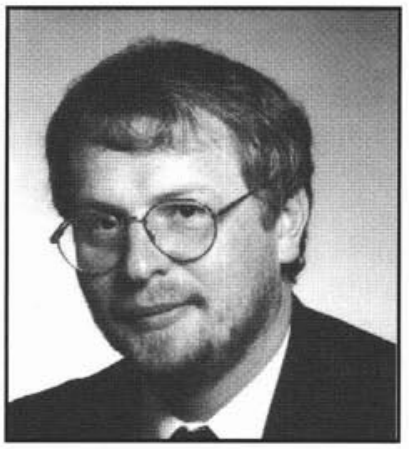

Glen Armstrong centage share of the AAC. Many FMUs support multiple quota holders, and many quota holders operate in several FMUs. Forest management planning for quota holders is a provincial responsibility. FMA areas and FMUs are not coextensive: typically, FMA areas are much larger than an FMU, and overlap several FMUs.

Until the mid-1980s, there was little commercial use of the hardwood tree species in Alberta (primarily trembling aspen 
(Populus tremuloides Michx.), balsam poplar (Populus balsamifera L.), and white birch (Betula papyrifera Marsh.). Forest tenures were established considering only land that supported commercial softwoods, primarily white spruce (Picea glauca (Moench) Voss), lodgepole pine (Pinus contorta var. latifolia Engelm.), black spruce (Picea mariana (Mill.) B.S.P.), and jack pine (Pinus banksiana Lamb.). Hardwoods were considered non-merchantable and land supporting nearly pure hardwood stands was considered non-productive. Since that time, however, new pulp mills and oriented strand board plants capable of utilizing the hardwood resource were constructed. Rights to the hardwood resource were established as new FMAs overlaying pre-existing quotas, or as deciduous quotas within existing FMA areas. One consequence of this overlap was the need to define the hardwood and softwood land bases. This has been done stand by stand, on the basis of forest inventory attributes.

An extremely complex example of the present allocation of resources is provided by the Alberta-Pacific Forest Industries Inc. FMA area (the FMA, henceforth). The FMA encompasses $74000 \mathrm{~km}^{2}$ of mostly boreal mixedwood forest (Strong 1992) in northeastern Alberta, Canada. The FMA is the timber supply area for a large bleached kraft pulp mill using mostly hardwoods, and numerous sawmills which use softwoods, mostly white spruce at present (Bamsey 1988). After some aggregation, we recognize the pulp mill and 17 distinct softwood-using firms, located at seven geographic locations, and having quotas within one or more of 21 FMUs (Fig. 1). The aggregate required timber flow is 1.55 million $\mathrm{m}^{3}$ of softwood and 2.36 million $\mathrm{m}^{3}$ of hardwood. Alberta Pacific requires $20 \%$ softwood in its mill furnish.

The FMA is effectively partitioned into five zones, each containing all or part of several FMUs ${ }^{3}$. The zones differ in the relative allocation of the conifer land base between AlbertaPacific, quota holders, and other users. The criteria for dividing the land bases and for determining regeneration standards differ between zones. In some instances, hardwood stands must be reforested as softwood, and so will shift to the softwood land base after harvest. This mix of rights and responsibilities has created an extremely complicated forest management situation. In a sense, Alberta-Pacific is responsible for the planning and management of the entire FMA, but the outcomes are dependent, to a large degree, on the activities of the quota holders operating independently within the FMA. The forestry decisions made by each of the 18 firms will have some impact on all the others. This is likely to introduce some inefficiencies into the system.

The arbitrary division of the area into softwood and hardwood land bases is problematic on economic and ecological grounds. The usual model of succession for the mixedwood describes a relatively pure aspen stand establishing after disturbance, with white spruce gradually developing in the understory, leading to a relatively pure white spruce stand after many decades (see Cumming et al. 2000, for a current review). However, reforestation standards for the coniferous land base mandate the rapid establishment of a pure coniferous stand.

\footnotetext{
${ }^{3}$ The Alberta Pacific Forest Management Agreement, Province of Alberta, Order in Council 556/91.

${ }^{4}$ Contact S.G. Cumming for more information about Tardis and its availability.
}

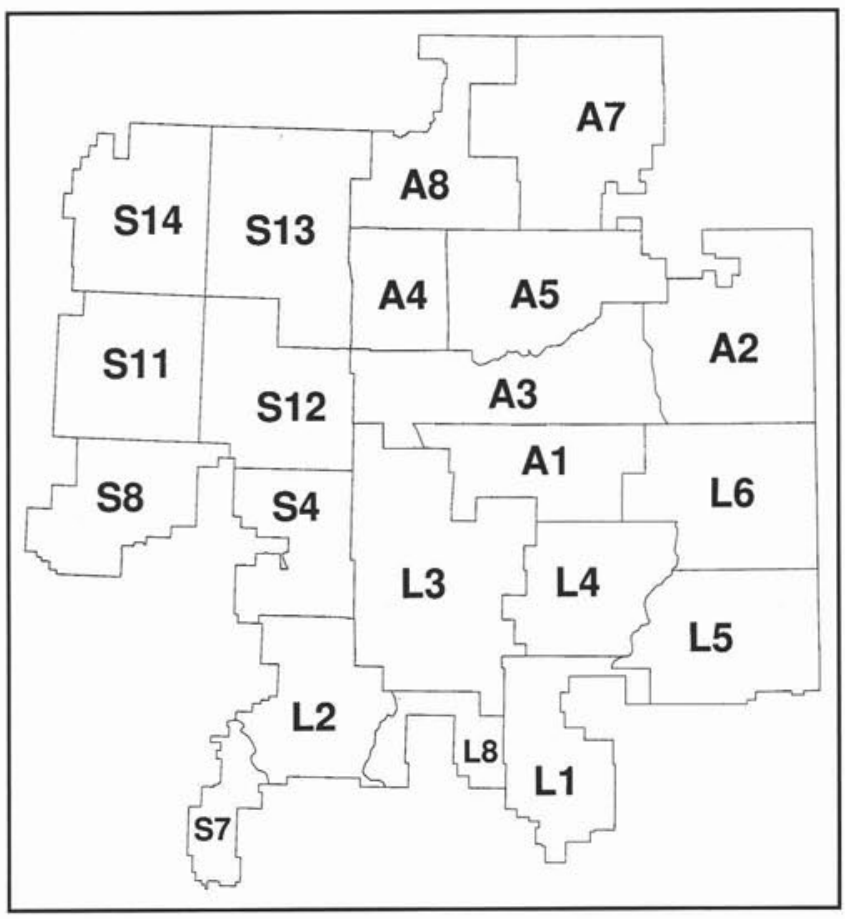

Fig.1. An outline map of the study FMA c. 1997, with its intersecting FMUs.

This requires great effort (e.g., mechanical site preparation, vegetation control using herbicides, and planting) and expense to fight what seem to be the ecological system's natural dynamics. As well, some wildlife species, forest birds in particular, are evidently dependent upon, or prefer, mature mixed stands of deciduous and conifer, or deciduous stands containing at least some proportion of mature white spruce (Schmiegelow and Hannon 1999). The current policy of "unmixing the mixedwood" entails a regional-scale decline in habitat quality or availability for such species.

Here, we describe a simulation study that compared the existing tenure arrangements (business-as-usual) against an alternate policy (global management) where a single agent is responsible for forest management, and for supplying all mills with timber. Our simulations used Tardis, a low-resolution spatial timber harvest scheduler developed by the lead author ${ }^{4}$. Tardis has previously been used to evaluate the effects of uncertainty in inventory and growth and yield data on the sustainability of timber supply (Joy 1995). Tardis is written in the $\mathrm{C}$ programming language (Kernighan and Ritchie 1988 ) and runs under the UNIX ${ }^{\text {TM }}$ operating system.

\section{Conceptual Model}

In this section, we outline the conceptual model underlying the current version of Tardis. More specific details of the various model components and data requirements are given below. The model is described in considerably more detail in Cumming and Armstrong (1999).

A forest estate is modelled as a collection of spatially referenced compartments on which a harvest scheduler operates. Here compartments correspond to townships, but this need not be the case in general. Compartments are composed of treatment units whose principal attributes are land base, yield 
curve, age, area, and treatment history. Treatment units correspond roughly to forest stands. The land base attribute determines the industrial use(s) to which the treatment unit may be allocated (e.g., pulp or saw timber production, or both). Harvestable volumes, species mix and harvesting and regeneration costs are determined from the yield curve and associated descriptors, and from the age attribute. Different regeneration and succession rules may be associated with each yield curve. At model start-up, when inventory records are processed, all stands within a compartment having the same yield curve, age and history are aggregated into a single treatment unit. Multipass harvest schedules are implemented at the treatment unit level, by partitioning the total area of the unit into two or more parts. Treatment units are dynamically aggregated and disaggregated as harvesting, ageing or succession dictate. Treatment history tracks succession (as from one yield class to another), harvesting and (in other applications) burning. The yield curves and succession rules constitute an implicit patch-level model of landscape dynamics with no spatial interactions.

The forest industry is modelled as a collection of agents, each of which has rights to harvest on specific areas of the simulated forest or estate. These rights may be restricted to the softwood or hardwood land base, or may include both. Each agent attempts to supply one or more demands from the areas where it has timber rights. Demands correspond roughly to individual mills and are chiefly characterized by a periodic volume requirement for either softwood or hardwood. Demands also specify the industrial use to which their periodic volume will be put (i.e., pulp or saw timber). This attribute is needed because of the stumpage rate structure currently in force in Alberta, where different stumpage rates are charged based on the mill type to which logs are delivered ${ }^{5}$. Each demand centre has a location, which corresponds to the geographic position of a mill. Location is represented by a raster map, whose entries are the distances from each compartment to the mill or mills. Haul costs are computed from these distances. A demand's specification includes the applicable stumpage rates, and (optionally) preferences for the various conifer species, relative to the most intensively harvested and desirable white spruce (Bamsey 1988). Finally, additional spatial rules may constrain a certain proportion of periodic volume to come from specific sub-regions within their operable area. The purpose of this feature is to model some of the larger sawmills in the study area, which have quotas in several FMUs.

Agents schedule harvests to satisfy multiple demands by greedy optimization (Baase and Van Gelder 2000). Combinations of operable compartments and demands are determined, a preference-weighted harvest revenue and delivered wood cost is estimated for each combination, and the highest net benefit (or least cost) choice is selected. This is repeated until periodic volumes are delivered, or no operable compartments remain. The case where each agent serves a single demand centre represents our business-as-usual scenario, with limited interaction between the various quota and FMA holders. The alternate policy of global management is simulated by defining a single agent to serve all FMA and quota holders currently operating in the study area, and by relaxing most spatial constraints.

\footnotetext{
${ }^{5}$ See http://www.gov.ab.ca/env/forests/fmd/directives/index.html for the current and historical rate structures.
}

\section{Data and Simulation Parameters}

The primary input data set is a stand list, spatially organized into compartments. Each entry in the list specifies the stand's compartment, yield class, land base, age and size. Size is measured as gross and net operable area. The data set we used contained 357968 stand records, of total gross area 3.93 million ha and total net area 2.39 million ha. Low-site black spruce and pine comprised $74 \%$ of the area netted out. The mean proportional netdown per township was $38.5 \%$ by area. Only the net area was considered operable in our simulations.

Yield classes are defined by tables of harvestable volumes of softwood and hardwood, in units of $\mathrm{m}^{3} \mathrm{ha}^{-1}$ in 10-year age classes. The data provided for this study specify 193 distinct yield classes, reflecting a fine stratification of the merchantable forest by species mix, crown closure, site quality and ecological region (Strong 1992), as well as the spatially variable land base and regeneration rules. The yield tables were developed for Alberta-Pacific by Timberline Forest Inventory Consultants Ltd. (Anonymous 1994a, b) using the Stand Projection System ${ }^{\mathrm{TM}}$ (Arney 1993). Each yield class has associated regeneration and succession rules, as well as minimum and maximum operability ages.

The behaviour of agents is controlled by specifications contained in an ordinary text file, which follows a simple keyword/value grammar. For the full text of the specifications used in the present study, with annotation, see Cumming and Armstrong (1999).

The key global parameters are a number of map files, in a format similar to ARC/INFO ASCII maps. The most important is the region map, which binds individual compartments to named geographic regions, such as FMUs. Exclusion zones (if any) within the region and initial road access are specified by two more maps. Then, one or more agents are named and defined. Each is given rights to harvest one or both land bases in one or more of the geographic areas named in the region map. For each agent, one or more demand centres are defined. Their attributes include their industrial activity (e.g., sawmill or pulpmill), a haul distance map (that specifies the distance from each compartment to the destination mill, based on the initial road network), and their periodic volumes. Optionally, the total volume requirements may be partitioned among the regions: this is how demands with quotas from several FMUs are defined. Stumpage rates are specified, as determined from published tables. Finally, the relative preferences for various conifer species are specified. For sawmills, preference values are 1.0 for white spruce, 0.8 for pine, 0.4 for black spruce (J.A. Beck, personal communication, 1998), and zero for larch and hardwoods All species are assumed to have equal value for pulp production.

\section{Delivered Wood Costs}

Tardis tracks several of the costs of forest operations, including access development, haul, logging, reforestation, cutblock layout, inventory, and stumpage costs, in order to estimate delivered wood costs. An accessible compartment is one that is either connected to the road network, or is adjacent to a connected compartment. Extending the road network into an unroaded accessible compartment costs $\$ 100000$. Roading charges accrue to the first agent scheduled to operate within a previously unroaded compartment, at the time of first entry. Haul costs ( $H$ expressed in $\$ / \mathrm{m}^{3}$ ) are computed from haul dis- 
tances by the formula $H=6.0+0.05 x$ where $x$ is haul distance $(\mathrm{km})$. Logging costs $\left(\$ / \mathrm{m}^{3}\right)$ are approximated by an adjusted version of the tree-to-truck cost equation developed by Beck et al. (1987):

$$
c=0.71(8.95-2.62 \ln s)
$$

where $\mathrm{s}$ is mean tree size $\left(\mathrm{m}^{3}\right)$. The variable $s$ is estimated from yield table entries by species-specific non-linear regression models (Cumming and Armstrong 1999). The adjustment factor of 0.71 is based on cost information provided by Alberta-Pacific. A base restocking charge of $\$ 50 /$ ha is assessed against all logging. Additional regeneration costs depend on the amount of white spruce desired at the site. This is measured by $s$, the proportion of conifer volume in the specified regeneration yield class at the minimum harvest age for that class. It is assumed that, on average, a certain "free" volume of white spruce will develop by this time. An effort of $\$ 2000$ per ha is assumed to produce a pure white spruce stand by the minimum harvest age. Total regeneration costs (\$/ha) are given by

$$
(r=50+2000 \times \min (0, s-0.1),
$$

where $s$ is the desired proportion of spruce in the stand at harvest, and the factor of -0.1 represents assumed natural regeneration

At the beginning of each entry to a compartment, cutblock layout costs of $\$ 100 / \mathrm{ha}$ of net land base are levied. At the beginning of each planning cycle (or rotation) on the hardwood land base, a one-time charge of $\$ 20000$ per compartment is assessed. This reflects the costs of (re-)inventory that, in the study area, are mostly borne by Alberta-Pacific. Stumpage is assessed against all harvested volume. Stumpage rates have three company-specific components: softwood stumpage, hardwood stumpage, and a special case for softwood stumpage which applies to softwood volume that is logged from the deciduous land base and subsequently sold as incidental harvest.

Monospecific timber stands are rare in the boreal mixedwood. There are often many merchantable deciduous trees in stands belonging to the coniferous land base and many merchantable coniferous trees in stands belonging to the deciduous land base. It is these trees, when harvested, which comprise the incidental harvest.

\section{Harvest Scheduling}

Tardis runs on a five-year time step. Each time step begins with a two-part planning stage. The first stage simulates a multipass harvesting plan, in which treatment units are allocated between passes. This stage is controlled by the planning state of the compartments, described below. In the second stage, Tardis determines the harvestable volumes under the current plan, and the associated logging and regeneration costs.

Compartments have four components: the hardwood and softwood land bases, and pools of incidental hardwood and softwood previously logged but not yet delivered, sold or lost to decay. Each land base component is always in one of four planning states: NOPLAN means that a component has either never been planned or that a multi-pass plan has been completed; READY means that a plan exists and a pass may be initiated; ACTIVE means that a pass is in progress; and GREENUP means that a pass has been completed, but the component is on hold pending a green-up delay. The two land bases may be planned and scheduled independently. The first stage of planning is applied to any component that is in state NOPLAN or is READY without the first pass having started. The result is that accessible compartments are continually replanned until a pass is initiated by some agent. Once a plan is initiated, it must be completed. The actual process of planning or replanning a land base is simple. Operable treatment units are divided equally amongst the passes, unless the unit is small, in which case it is allocated entirely to one of the passes, on a round-robin basis. The effect is that, within compartments, passes are roughly of equal area.

In the second stage of planning, harvestable volumes and costs are computed. For each treatment unit, the area allocated to the current pass is translated into merchantable hardwood and softwood volumes through the yield tables. The total available volume by leading softwood and hardwood species is calculated. Regeneration and logging costs for the operable treatment units are computed. The result is that the total available volume and species mix, and the total logging and regeneration costs of initiating (or completing) the current pass on each compartment, are available to the scheduler.

The scheduler serves agents round-robin, until for each agent, all periodic demands have been satisfied, or else no operable units remain. For each agent, a scheduling step consists of selecting a compartment and a plan, executing the plan, and distributing the harvested volume amongst some combination of a conifer and a deciduous demand centre and the compartment's pools of incidental wood. The selection step consists of generating a list of all currently feasible plans, and then sorting it by an optimality criterion, explained below. It is primarily this sorting step, which determines the best action to take next, that defines the scheduler as a greedy optimizer.

The list of feasible plans is constructed as follows. A compartment is operable for an agent if the agent has rights to at least one of the two land base components, and at least one component is either in state READY or else has previously been placed in state ACTIVE by the agent. This last rule prevents agents from pre-empting each other during completion of a pass. For each compartment, the agent may have one or more demands still in need of delivered wood, but not excluded from the compartment by a spatial rule. For example, in the present study, under business-as-usual, there is at most one demand to consider, while under global planning there can be up to 18 (one pulp mill and 17 quota holders.) For each demand, or pair of conifer and deciduous demands, between two and eight plans are possible, depending on whether one or both land bases are harvested, and on the disposition of the incidental cut (for details, see Cumming and Armstrong 1999.) The final list is composed of all such plans, for all combinations of demands, over all operable compartments. Each plan has associated costs and benefits. The plan with the highest net return to the agent is chosen, except that active compartments have priority. Passes may span several model time steps, but cannot be deferred for too long.

Net returns are computed as follows. Logging, regeneration and stumpage costs associated with a plan are assigned to demand centres according to the following two principles:

(1) the demand centre for which a treatment unit is cut pays all logging, regeneration and stumpage costs. 
(2) if any proportion of the total realized volume is allocated to another demand centre, either directly or as incidental material purchased at a later step, it repays the logging and regeneration costs pro rata by volume, plus the stumpage originally paid for the redirected wood.

Haul costs for each demand centre and compartment are computed from the demand centre-specific haul distance maps. Planning and roading costs if any, are charged to the demand centre(s) receiving material from a compartment, pro rata by volume. As the total volumes available under each plan are known, the delivered wood costs per $\left(\$ / \mathrm{m}^{3}\right)$ for softwood and hardwood $\left(c_{c}\right.$ and $\left.c_{d}\right)$ can be determined. The net return for a plan is then:

$$
r=\frac{v_{c}\left(f r_{c}-c_{c}\right)+v_{d}\left(r_{d}-c_{d}\right)}{v_{c}+v_{d}}
$$

where $v_{c}$ and $v_{d}$ are the available volumes, $r_{c}$ and $r_{d}$ are the estimated revenues, and $f$ is a conifer weighting coefficient, computed from the species mix of and the conifer demand centre's species preferences. In the case where a single demand centre is being evaluated, either $v_{c}$ or $v_{d}$ is zero, and $r$ reduces to the (possibly preference-weighted) revenue less cost. If millspecific production functions and demand curves are known, Tardis can compute marginal revenues, in which case $r$ is the marginal return, given the amount of wood already delivered in a time step. However, the necessary data to implement this feature were not available at the time of this study. We therefore assumed fixed revenues of $r_{c}=\$ 60 / \mathrm{m}^{3}$ for softwood and $r_{d}=\$ 50 / \mathrm{m}^{3}$ for hardwood. These are estimates of the usual upper limit for mill gate prices, appropriate for the study area (D. Cheyne, Management Forester, Alberta-Pacific Forest Industries, personal communication, 2000). As marginal revenues could not be computed, we will report delivered wood costs only. This reflects the current regulatory environment, which requires FMA and Quota holders to realise their allocations. Changing the values of the fixed revenues would only alter the relative priorities with which conifer and deciduous demands are served by the scheduler, but would not otherwise affect our conclusions.

\section{Scenarios}

We considered eight scenarios representing all combinations of three alternatives:

1) Global vs. spatially constrained scheduling;

2) Softwood species preferences for quota holders on or off;

3 ) White spruce regeneration delays of 20 years, or no regeneration delay

To make the number of comparisons between scenarios tractable, we first evaluated the effect of quota holder softwood species preferences, under business-as-usual, to select one option for further study. This left four cases determined by alternatives (1) and (3). All scenarios were run over a 200 -year planning horizon, unless otherwise specified. Discounted cost calculations assumed a 5\% discount rate. In all cases, we assumed a two-pass clearcut harvesting system, with a minimum of 10 years of green-up between passes. Scenarios were evaluated using four criteria:

1) the ability to satisfy all periodic demands;

2) the species mix provided to quota holders;

3) the annual cost flows and/or the present value of costs;

4) the "footprint" of harvesting activity.

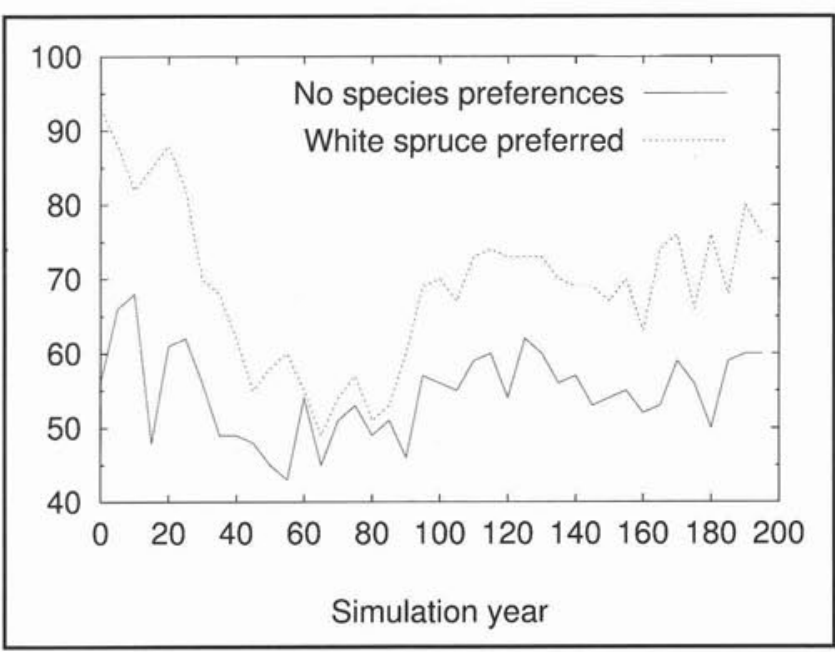

Fig. 2. Mean proportion of white spruce in delivered quota volumes, with and without white spruce preferences, under business-as-usual scheduling.

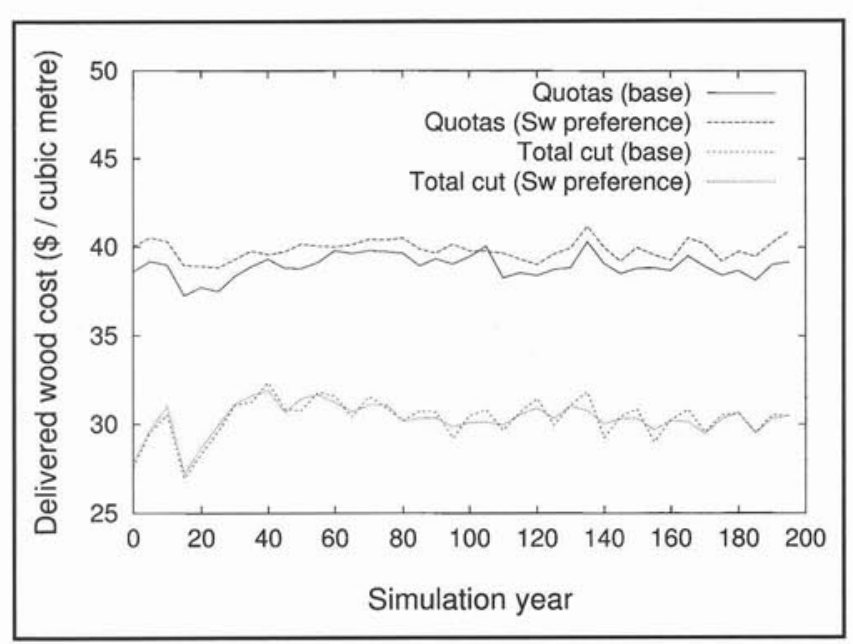

Fig. 3. Mean delivered wood costs for quotas and for the total harvest, with and without white spruce preferences, under business-asusual scheduling.

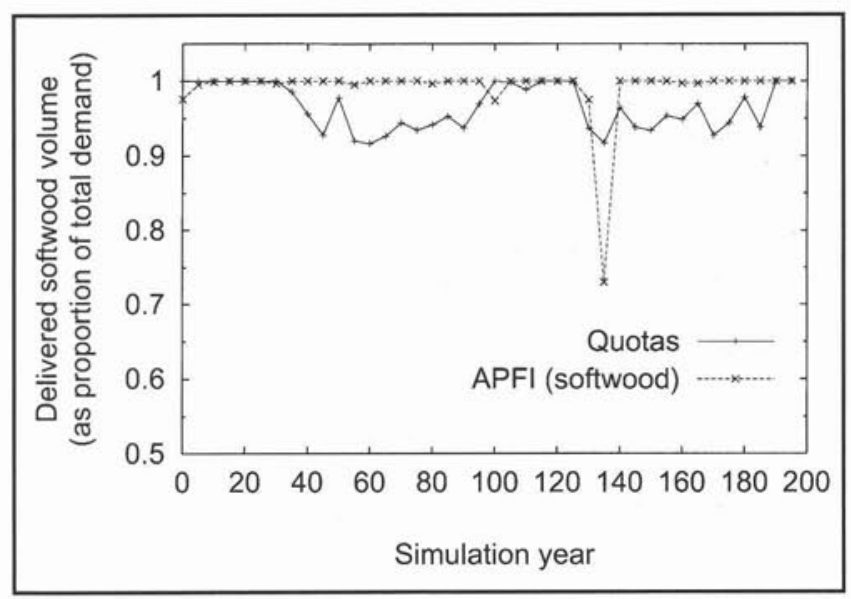

Fig. 4. Delivered softwood volumes to quota holders and AlbertaPacific, expressed as proportions of periodic demand. 

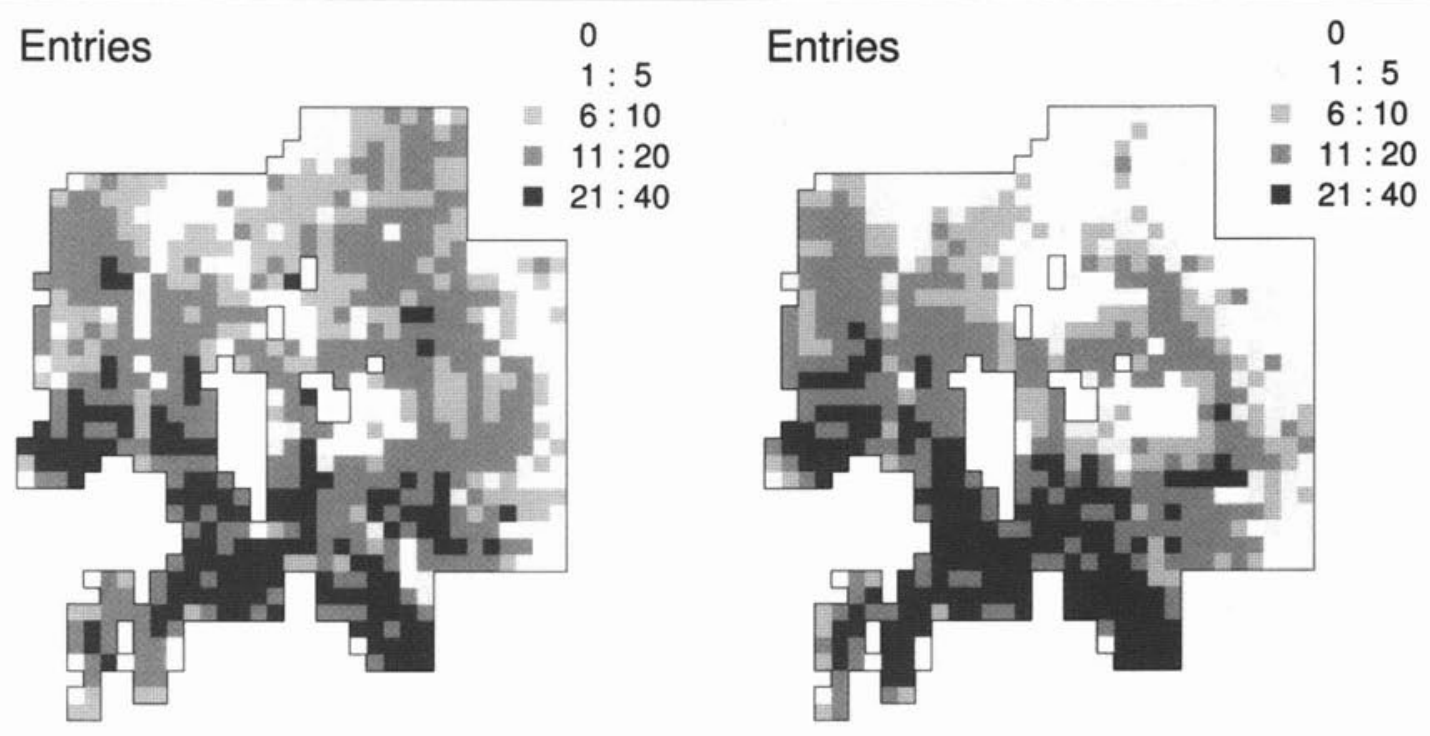

Fig. 5. Spatial pattern of township entries over 200 years. Left: the base scenario. Right: the global scheduling scenario. Note the exclusion zones in the middle of the FMA, mostly associated with large wetland complexes.

\section{Results}

\section{Effect of white spruce preferences}

The mean white spruce content of quota holder mill furnish over the simulation was $54.6 \%$ without species preferences, and $69.1 \%$ with white spruce preferences (Fig. 2). In the base case, the average proportion of white spruce in the softwood component of Alberta-Pacific's mill furnish was $48 \%$. Under quota holder white spruce preferences, it was only $30.5 \%$. From the actual species composition taken by quotas in the FMA (Bamsey 1988), we conclude that simulations with a white spruce preference on the part of quota holders better represent actual forest planning objectives. If Alberta-Pacific is indifferent to softwood species mix, simulated schedules with quota holder white spruce preferences make more efficient use of the available white spruce resource. The projected decline in delivered white spruce volume suggests that current rates of white spruce harvest are unsustainable.

Honouring white spruce preferences does not entail increases in total delivered wood costs (Fig. 3). Although delivered wood costs to the quota holder increased from $\$ 38.92 / \mathrm{m}^{3}$ to $\$ 39.85 / \mathrm{m}^{3}$, the change in total costs in negligible. The main reason for this is a shift in white spruce restocking charges from Alberta-Pacific to various quota holders, as incidental harvest of this species is directed more fully to these users. Since white spruce preferences evidently produce more desirable softwood allocations under business-as-usual scheduling, and entail no net cost, we adopt this case as our baseline scenario.

\section{Performance of the baseline scenario}

Under the baseline scenario, the harvest scheduler could not always deliver the specified periodic volumes of softwood, either to quota holders, or (for one time period) to Alberta-Pacific (Fig. 4). Periodic volume demands for hardwood were satisfied to within $0.5 \%$ over the simulation. Softwood shortfalls occurred as early as 30 years into the simulation, mostly affecting the demands drawn from FMU S14. One demand centre drawing from FMUs A5, A7 and A8 had a 16\% shortfall during the simulation period starting at 145 years. Volumeweighted mean delivered wood cost was $\$ 30.31 / \mathrm{m}^{3}$ over the planning horizon. A substantial area (96 townships) outside the exclusion zones was never scheduled for harvest over the planning horizon (Fig. 5).

\section{Performance of the global scheduler}

The global scheduler satisfied all periodic demands within a tolerance of $0.5 \%$. The proportion of white spruce in the softwood volume delivered to quota holders was slightly higher than under the base case (a long-run average of 69.9\%). Most of this gain (absolute increases of up to $10 \%$ per annum) was achieved over the first 30 years. Under the global scheduler, mean delivered wood cost was $\$ 28.98 / \mathrm{m}^{3}$ as compared to $\$ 30.31 / \mathrm{m}^{3}$ in the base case (Fig. 6), a long-run average savings of $\$ 1.33 / \mathrm{m}^{3}$. Greater cost savings are realized over shorter planning horizons: e.g., $\$ 2.26 / \mathrm{m}^{3}$ over the first 30 years, corresponding to mean annual savings of $\$ 7.6$ million. Assuming a 5\% discount rate, the present value of the cost savings between the global scheduler and the base scenario was approximately $\$ 140$ million. The savings accrued mostly from reduced average haul costs and a better allocation of incidental conifer, so that unrecovered stumpage was paid on a smaller volume. Haul costs were reduced by a spatial concentration of harvesting activity (Fig. 5), which result in 190 townships being left undisturbed by harvesting, compared with 96 townships in the base case. Global planning would probably reduce the overall level of activity in the forest. A total of 8938 harvesting plans were developed and executed in this scenario, compared to 14884 in the base case. Such a reduction in human activity may be desirable from a biodiversity conservation perspective. Also, additional savings could perhaps be realized from reductions in costs unaccounted for by the model. 


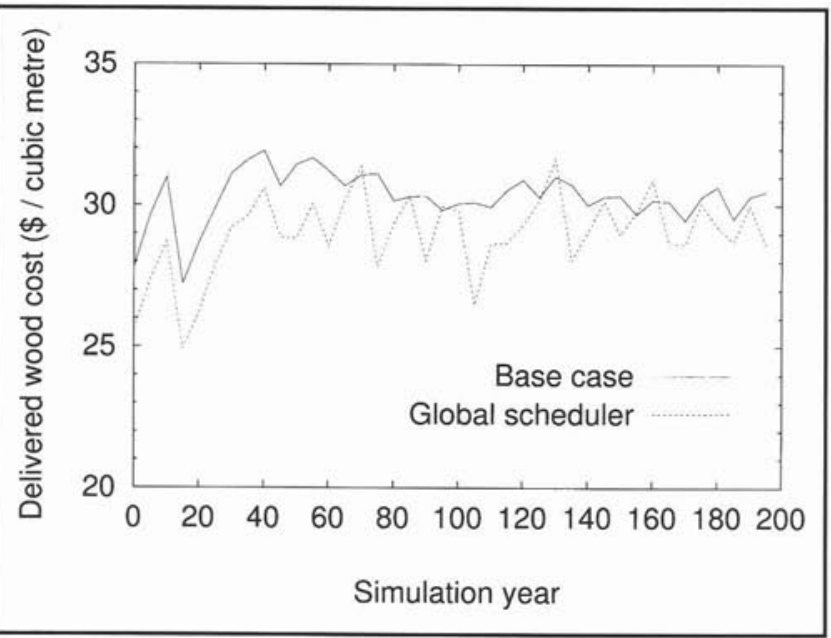

Fig. 6. Mean delivered wood costs under the base case and under global scheduling.

\section{Summary and Discussion}

The forest planning environment of the area within and surrounding the Alberta-Pacific FMA is one of the most complex in Alberta. In our somewhat aggregated view of the situation, we modelled 17 softwood quota holders and the AlbertaPacific pulp mill, trying to simultaneously satisfy their mill feedstock requirements from the FMA. The quota holders and the FMA holder plan and operate independently, which is inefficient. For example, more roads may be built, and more townships may experience logging activity, than is necessary. It also seems likely that relatively pure stands will be targeted for harvest more frequently than mixedwood stands, relative to their respective abundance. We examined these potential inefficiencies using Tardis, a computer simulation model incorporating access development, timber harvest, and regeneration. We simulated the business-as-usual case, where each quota or FMA holder attempts to satisfy its annual volume requirements in the most cost-effective manner possible, subject to spatial constraints. We compared this case with a simulated "global management" strategy, where a single agent is responsible for all forest management. The single agent allocates timber to the individual mills following a round-robin strategy, so that the mill where timber yields the next-highest net revenue (or, equivalently, next-lowest cost) gets the next timber allocation. The scheduler acts as a greedy optimizer, and attempts to simulate a globally near-optimal annual harvest schedule.

The most important results of the simulation experiments were:

1) Under business-as-usual, the FMA area is unable to meet softwood volume demand in many time periods. Under global management, there are no shortfalls.

2) The present value (using a 5\% annual discount rate) of the difference between delivered wood costs under the two scenarios is approximately $\$ 140$ million. Annual cost savings under a global strategy are approximately $\$ 7$ million. This value is about half the annualized stumpage revenue under business-as-usual (\$13.4 million). Under global management, stumpage fees could be increased by more than $50 \%$ without affecting the financial well being of the firms involved. Alternatively, cost savings could be passed on to the firms.
3) Under global management, 94 fewer townships were entered during the 200 -year planning horizon than under business-as-usual. This represents a substantial area that could be set aside for other uses (e.g., natural areas), or used to support an increased AAC.

4) The model predicts a substantial decline in the white spruce delivered to quota holders. This suggests that the current level of white spruce harvest is unsustainable without an increase in management effort and expense. Quota holders will likely need to adjust to a changing species mix (and corresponding log size distribution) in their mill furnish. Using the Tardis modelling environment, we have demonstrated some of the inefficiencies that are inherent in the current forest policy environment in Alberta and have quantified, in financial terms, some of the costs of these inefficiencies. The costs are, we believe, substantial enough to warrant a thorough examination of forest policy in Alberta, specifically with respect to land base designation and overlapping tenures. Furthermore, there are significant implications for landscape management and protected area design arising from our results, which merit further exploration.

As with any modelling study, ours could be refined. The various mills presumably have different production technologies and place different values on different types of timber. Incorporating the demand curves for individual mills would improve the efficiency of the simulated schedules. The yield curves for regenerated timber used in this study were fixed. However, a thorough examination of the costs and benefits of silviculture requires a suite of alternate regenerated yield curves corresponding to different levels of investment. Finally, the questions posed in this study may be better answered in an optimization framework; Tardis is a simulation model with little ability to address inter-temporal relationships. Hauer and Hoganson (1995) have developed a multi-agent optimization model that uses a spatial resolution similar to ours. Application of such a model to the problem studied here may add some additional insight.

\section{Acknowledgements}

Funding for this study was provided by the Sustainable Forest Management Network. Data were provided by AlbertaPacific Forest Industries, Inc. Tim Barker, Kim Rymer, Dave Cheyne, Vic Adamowicz, Jim Beck, Fiona Schmiegelow, and two anonymous reviewers provided helpful comments and suggestions.

\section{References}

Anonymous. 1994a. Stand projection system calibration for the mid boreal mixedwood ecoregion and the upper boreal mixedwood ecoregion. Tech. rep., Pearson Timberline Forestry Consultants, Edmonton, Alberta.

Anonymous. 1994b. Stand projection yield curves and yield classes for the mid boreal mixedwood ecoregion and the upper boreal mixedwood ecoregion. Tech. rep., Pearson Timberline Forestry Consultants, Edmonton, Alberta.

Arney J.D. 1993. SPS guide for the stand projection system (TM) (SPS) Version 2.4. Tech. rep., Mason, Bruce \& Girard, Inc., Portland, Oregon, USA.

Baase S. and A. Van Gelder. 2000. Computer Algorithms: Introduction to Design and Analysis. $3^{\text {rd }}$ edn. Addison Wesley Publishing Co., Reading, Mass.

Bamsey C.R. 1988. Directory of primary wood-using industries in Alberta 1988. Alberta Forest Service and Forestry Canada, North. For. Cent., Edmonton, Alberta. 
Beck J.A., R.G. Anderson, G.W. Armstrong and G.H. Farrow. 1987. Alberta economic timber supply study: Final report. CanadaAlberta forest resource development agreement, Supply and Services Canada, Ottawa.

Cumming S.G. and G.W. Armstrong. 1999. Divided land bases and overlapping tenures in Alberta's mixedwood forests: a simulation study of a policy alternative. Working Paper 1999-3, Sustainable Forest Management Network, Edmonton.

Cumming S.G., F.K.A. Schmiegelow and P.J. Burton. 2000. Gap dynamics in boreal aspen stands: is the forest older than we think? Ecological Applications 10: 744-759.

Hauer G.K. and H.M. Hoganson. 1995. Tailoring a decomposition method to a large forest management scheduling problem in northern Ontario. INFOR 34: 209-231.
Joy M.W. 1995. Handling uncertainty in GIS and environmental models: an application in forest management. Master's thesis, Department of Geography, University of British Columbia, Vancouver, BC.

Kernighan B.W. and D.M. Ritchie. 1988. The C Programming Language. 2nd edn. Prentice-Hall, Englewood Cliffs, New Jersey.

Schmiegelow F.K.A. and S.J. Hannon. 1999. Forest-level effects of management on boreal songbirds: the Calling Lake fragmentation studies. In J.A. Rochelle, L.A. Lehmann and J. Wizniewski (eds.). Forest Fragmentation: Wildlife and Management Implications. Brill, Lieden.

Strong W.L. 1992. Ecoregions and ecodistricts of Alberta. ENR Technical Report T/244, Alberta Forestry, Lands and Wildlife. 